\title{
A TRANSMISSÃO AO VIVO DE CAMPEONATOS DE SURFE PELA INTERNET: PADRÕES TELEVISIVOS, INOVAÇÃO E QUESTÕES PARA A HISTÓRIA DO ESPORTE
}

\author{
The webstreaming of surfing contests: television standards, innovation and \\ questions for the history of the sport
}

\author{
Pedro Cezar Duarte Guimarães ${ }^{1}$ \\ Rafael Fortes ${ }^{2}$
}

\begin{abstract}
RESUMO
As transmissões esportivas ao vivo por meio de radiodifusão pública (televisão aberta e rádio) têm sido um objeto negligenciado pelos estudos históricos do esporte. Neste trabalho, abordamos uma modalidade esportiva que rarissimamente foi transmitida por televisão e rádio, mas que, nos últimos 15 anos, passou a sê-lo por meio da internet: o surfe. $\mathrm{O}$ artigo encontra-se dividido em três partes. A primeira trata do ao vivo, característica historicamente relevante da televisão; das articulações entre o ao vivo e a imediaticidade do ao vivo esportivo; e da relação entre a convergência tecnológica e as transmissões ao vivo por streaming. Na segunda parte, discutimos características das competições de surfe que, historicamente, tornaram-nas um desafio para as transmissões televisivas ao vivo; e descrevemos a plataforma/aplicativo da Liga Mundial de Surfe (World Surf League - WSL) e seu funcionamento técnico. Por fim, examinamos o corpus: a transmissão da bateria final do Corona Open J-Bay 2017, etapa do Circuito Mundial masculino de surfe. A descrição e análise exploram práticas adotadas na transmissão e dados do aparato audiovisual e do esforço tecnológico mobilizados pela plataforma WSL. Entre os nossos objetivos está compreender como os padrões clássicos da transmissão esportiva televisiva ao vivo dialogam com as práticas de exibição de campeonatos de surfe on-line. Para tanto, utilizamos uma bibliografia que inclui estudos históricos do esporte e discussões em torno das possibilidades de espectatorialidade propiciadas pela tecnologia streaming e dos aspectos consolidados no léxico das transmissões esportivas teorizados por Garry Whannel.
\end{abstract}

Palavras-chave: história do esporte, história da comunicação, Liga Mundial de Surfe.

\begin{abstract}
Live sports broadcasting on television and radio has been an object neglected by the sport's historical studies in Brazil. In this work, we approach a sport that was rarely

1 É mestre em Comunicação pelo Programa de Pós Graduação da Universidade Federal Fluminense. Possui graduação em Comunicação Social pelo Centro Universitário da Cidade (1992). É diretor e roteirista de cinema, publicidade e projetos ins-

2 Doutor em Comunicação com pós-doutorado em História. Bacharel em História. E-mail: raffortes@hotmail.com. ORCID:
\end{abstract} titucionais. E-mail: pedrusergiu@gmail.com. http://orcid.org/0000-0001-7071-3725. 
broadcast on television and radio, but that, in the last 15 years, has been broadcast over the internet: surfing. The article is divided into three parts. The first deals with live transmission, a historically relevant feature of television; the articulations between live and the immediacy of sports live; and technological convergence and live streaming. In the second part, we discuss characteristics of surfing and competitions in this activity that, historically, made it a challenge for live television broadcasting; and we describe the World Surf League platform/application, and its technical operation. Finally, we examine the webcasting of Corona Open J-Bay 2017 final, an event stage of the men's surfing World Tour. The description and analysis include practices adopted in the transmission and data of the audiovisual apparatus and technological effort mobilized by the WSL platform. One of our goals is to understand how the classic standards of live sports broadcasting appear within the webcasting of surfing championships. To do so, we use a bibliography that includes historical studies of the sport and debates about the possibilities of spectatorial provided by streaming technology and the lexicon of sports transmission theorized by Garry Whannel.

Keywords: Sport History; Communication History; World Surf League.

\section{Introdução}

Embora ocupem, há décadas, muitas horas da programação dedicada ao esporte no rádio e na televisão, as transmissões ao vivo raramente foram objeto de pesquisa no Brasil, na História e na Comunicação. Na medida em que consideramos correto afirmar, tanto para o Brasil quanto para outros países, que "certamente muito do que sabemos e compreendemos sobre esporte é modelado pela mídia”, a lacuna torna-se importante (Kinkema e Harris, 1998, p. 27).

A relação entre mídia e esporte data da configuração do campo esportivo. Segundo Miller et al. (2001), houve uma relação de influência mútua: "esporte moderno e mídia se desenvolveram simultânea e simbolicamente, provendo um ao outro os recursos necessários ao desenvolvimento: capital, público, divulgação e conteúdo" (p. 62). Ambos estão profundamente ligados à emergência de sociedades urbanas e industriais, tendo sido a mídia a instituição que mais contribuiu para o "crescimento espetacular do esporte" no século XX (Goldlust, 2004, p. 27; Rowe, 2004, p. 6). Melo $(2001,2012)$ argumenta que processo semelhante se deu em território brasileiro, particularmente na capital, Rio de Janeiro.

Desde o século XIX, principalmente nos EUA e em países da Europa Ocidental, "numerosos jornais e revistas esportivos [...] ajudaram a formar as subculturas esportivas que cresceram em torno de certos jogos e competições", como o boxe e o turfe (Goldlust, 2004, p. 40). No século XX, o rádio e a televisão foram centrais para o esporte transformar-se em interesse de multidões espalhadas por numerosos países e todos os estratos sociais. Nas décadas finais do século, o vídeo, os videogames e as possibilidades oferecidas pelo acesso individual e coletivo à internet, entre outros, aprofundaram e diversificaram as instâncias de mediatização, exploração comercial e popularização do fenômeno esportivo - algumas das quais se modificaram à medida que se avança no século XXI.

Em meio a essas possibilidades, decidimos investigar as transmissões ao vivo de 
competições de surfe disponibilizadas na plataforma da WSL. ${ }^{3}$ Partindo da premissa de que as transmissões esportivas ao vivo por streaming engendram uma complexa rede envolvendo participantes on-line, sites, redes sociais digitais, dispositivos audiovisuais e estruturas de telecomunicações, buscamos articular nossa análise com pesquisas sobre história do surfe, história das transmissões esportivas, estudos do audiovisual e características das transmissões on-line. Para tanto, o presente trabalho está dividido em três partes.

Na primeira, abordamos o ao vivo, característica fundacional da televisão e referência importante na segunda metade do século XX e no presente. Prosseguimos tratando de suas articulações com a imediaticidade do ao vivo esportivo. Encerramos o item discutindo a convergência tecnológica e as transmissões ao vivo por streaming, com suas potencialidades e variantes de espectatorialidade.

Na segunda parte, discutimos características do surfe e das competições desta modalidade que, historicamente, a tornam um desafio para as transmissões televisivas ao vivo. Em seguida, descrevemos a plataforma/aplicativo da WSL e seu funcionamento técnico.

Por fim, examinamos o corpus: a transmissão da bateria final do Corona Open J-Bay 2017, explorando práticas adotadas e dados do aparato audiovisual e do esforço tecnológico mobilizados pela WSL. A referida transmissão foi exibida em 20 de julho de 2017 na plataforma on-line e pelo aplicativo da WSL. ${ }^{4}$ Em março de 2020, um vídeo contendo a íntegra da transmissão permanecia disponível, ${ }^{5}$ como um dos recursos que o site da WSL oferece. O mesmo ocorria com todas as transmissões de etapas de 2015 a 2019. Essa condição - conteúdo on-line, integral, aberto e gratuito, anos após a realização dessas - oferece uma oportunidade raríssima para os pesquisadores do esporte, considerando a notável dificuldade de acesso a arquivos de transmissões, principalmente no que tange à radiodifusão ao longo do século XX. Trata-se de uma postura inusual entre as entidades esportivas e/ou detentoras dos direitos de transmissão das competições. Contudo, não sabemos por quanto tempo essa documentação permanecerá disponível de forma aberta e gratuita.

\title{
1. O ao vivo e a televisão
}

Os estudos televisivos chamam com frequência a atenção para a onipresença das transmissões ao vivo nos primórdios da televisão. Conforme Machado (2000):

\begin{abstract}
A televisão nasceu ao vivo, desenvolveu todo o seu repertório básico de recursos expressivos num momento em que operava exclusivamente $a o$ vivo e esse continua sendo o seu traço distintivo mais importante dentro do universo do audiovisual. A partir da televisão (como já acontecia com o rádio, no plano da transmissão sonora), o registro de um espetáculo, a sua edição e a sua visualização por parte da comunidade de espectadores
\end{abstract}

\footnotetext{
3 A WSL é uma entidade privada - uma liga que organiza os principais circuitos de surfe do mundo, bem como circuitos continentais. Em 2013, foi comprada por três milionários. Posteriormente, um deles se retirou, ficando um casal como donos. Até 2016, chamava-se Associação dos Surfistas Profissionais (ASP).

4 Disponível em: <http://www.worldsurfleague.com>. Acesso em 15 dez. 2019.

5 Disponível em: http://www.worldsurfleague.com/events/2017/mct/1900/corona-open-j-bay/heatanalyzer>. Acesso em 23 mar. 2020.
} 
podem se dar simultaneamente é esse justamente o traço distintivo da transmissão direta: a recepção, por parte de espectadores situados em lugares distantes, de eventos que estão acontecendo em outros lugares e nesse mesmo instante (p. 125).

Nas décadas de 1930 e 1940, todos os programas de televisão - do noticiário ao drama - foram transmitidos ao vivo (Auslander, 2008, p. 15; Caughie, 2000, p. 30-32).6 Durante décadas, antes que a tecnologia de gravação de imagens e som em fitas magnéticas (videotape) fosse criada, era impossível arquivar conteúdos televisivos. E, mesmo depois de a tecnologia ter permitido a gravação e apreensão de conteúdos audiovisuais, o ao vivo e seus valores intrínsecos (imediaticidade, senso de realidade e noção de presença, entre outros) mantiveramse centrais em diversos gêneros, sobretudo no noticiário e nos esportes. Portanto, as transmissões ao vivo são fundamentais para a compreensão do desenvolvimento estético do meio televisivo (Auslander, 2008).

A introdução de equipamentos de gravação, em meados da década de 1950, alterou as capacidades técnicas e a estética da televisão, bem como a disposição dos administradores para conceber, planejar e agendar programas, construindo grades de programação diária e semanal. A partir dessa mudança, a televisão se reconfigurou. As transmissões ao vivo, contudo, continuaram presentes e permanecem importantes para certos gêneros - como no imediatismo do noticiário e nos esportes, onde, respectivamente, $97 \%$ e $92 \%$, eram assistidos ao vivo na segunda metade do século XXI (Ofcom, 2013a, p. 148 apud Sorensen, 2016).

\subsection{O ao vivo e o esporte}

Garry Whannel (1992), pioneiro em pesquisas envolvendo televisão e esportes, observa que o jornalismo e a reportagem são elementos fundamentais da cobertura esportiva, e que o fenômeno esportivo tem seu próprio conjunto de valores noticiáveis, como imediatismo, imprevisibilidade e espontaneidade. O livro foi escrito na década de 80, quando o vídeo ampliara as possibilidades de registrar e arquivar conteúdos televisivos, originando o que o autor classificou como a era do vídeo. Segundo ele, o ao vivo, naquele período, continuou a ser um elemento retórico importante anunciado em transmissões esportivas na televisão.

Um aspecto que merece cuidadosa reflexão na obra de Whannel diz respeito à estrutura particular da narrativa esportiva, responsável, segundo ele, por fundar um "enigma inicial" capaz de legitimar o caráter "ao vivo" de qualquer transmissão de esportes, ao lançar a pergunta: “quem será o vencedor?”. A resolução desse conflito, em geral, só pode ser descoberta ao término do evento. A principal distinção entre uma narrativa ficcional e o desenrolar de um evento esportivo é que, no segundo caso, o resultado não é conhecido de antemão e não pode ser determinado por convenções prévias. O autor observa que os eventos esportivos existem independentemente da televisão e são acontecimentos que pertencem ao mundo real. São, portanto, ocorrências de natureza distinta de eventos concebidos ou produzidos

6 No Brasil, as transmissões televisivas iniciaram-se em 1950 e o videotape começou a ser utilizado no início da década seguinte (Mattos, 2002). 
especificamente por e para o meio televisivo. Para Whannel (1992), os eventos esportivos são sistemas demarcados, autônomos e de atividade regida por regras próprias - delimitados tanto no espaço quanto no tempo.

Temos que considerar que a perspectiva de Whannel foi elaborada há mais de 30 anos. Desde então, diferentes produtos e formatos relacionando esporte e audiovisual foram desenvolvidos. Em tempos de Big Brother Brasil e numerosos reality shows, podemos citar, pensando na presença do esporte na televisão, eventos que só existem no âmbito da transmissão televisiva (como The Ultimate Fighter) e/ou outros criados para preencher lacunas da programação (como as peladas de fim de ano disputadas em diferentes estádios do território nacional e transmitidas por canais esportivos de televisão fechada; os Jogos Mundiais de Verão transmitidos durante o Esporte Espetacular da Rede Globo em 2006-2007 entrariam nas duas categorias).

As relações mencionadas na introdução deste artigo e a evolução de um modus operandi particular de transmitir esportes constituem zonas de imbricação entre televisão esportiva e entretenimento. Em primeiro lugar, o alto grau de investimento e profissionalismo necessários para propiciar um espetáculo ao vivo, competente e atraente, são comuns aos dois. No caso de megaeventos esportivos, com a participação de equipes e jogadores de vários países, profusão de cenas com estético e difusão de imagens por satélite, o espetáculo ganha uma dimensão global.

Em segundo lugar, o intercâmbio entre atletas famosos marcando presença na TV fora dos horários, programas e canais dedicados ao esporte (por exemplo, em programas de auditório, novelas, seriados, programas de entrevistas e intervalos comerciais) e celebridades televisivas fazendo parte de eventos esportivos exemplifica a convergência entre as duas práticas. Em terceiro, por conseguinte, o tratamento do esporte ocupa um lugar peculiar no jornalismo. Para Whannel (1992), "o aspecto da reportagem vincula ainda a cobertura esportiva às convenções de neutralidade, imparcialidade, equilíbrio e objetividade. O esporte é, nesse sentido, mais uma forma segmentada de notícias". Na cultura profissional do jornalismo nos EUA e Canadá, problemas e conflitos sociais resultam comumente em notícias relevantes. Escrevendo no fim dos anos 1980, Gruneau (1989) afirmou que no noticiário esportivo a situação era distinta. O esporte era apresentado como um universo próprio, descolado da realidade sociopolítica. A ênfase residia na ocorrência regular de eventos e no inerente caráter positivo destes. Qualquer atividade que atrapalhasse o curso dos eventos era tida como negativa: boicotes, acidentes, decisões políticas, fenômenos meteorológicos, emergências policiais ou sanitárias. Embora problemas estruturais (racismo, misoginia e homofobia, por exemplo) e conflitos talvez tenham recebido mais atenção na cobertura esportiva desde então, as maneiras costumeiras de tratar o esporte sugerem que a observação do autor permanece atual.

Em quarto lugar, o esporte televisivo - que, em países como EUA e Brasil, está vinculado de maneira praticamente exclusiva à televisão privada com objetivos comerciais - lança mão de recursos em geral associados ao entretenimento para obter popularidade (atrair e manter largas audiências) e produzir prazer (Whannel, 1992, p. 58). O esporte é um assunto que pode ser trabalhado tanto jornalisticamente quanto como entretenimento, mantido separado das hard news (Boyle e Haynes, 2009, p. 26). Ponderamos que o tratamento televisivo do esporte, sobretudo as transmissões ao vivo, distancia-se dos padrões utilizados para outros assuntos por exemplo, ao enfatizar emoções (como a forma comemorativa e hiperbólica adotada por narradores para referirem-se a feitos dos atletas: gols, vitórias, pontos etc.). 
Em artigo produzido 25 anos após a publicação de Fields in Vision, Whannel (2005) observa que a transmissão televisiva ao vivo amadureceu e se consolidou a ponto de desenvolver um léxico próprio:

\begin{abstract}
Uma vez que o esporte na televisão atingiu sua maturidade, em torno do início da década de 1980, as convenções permaneceram relativamente inalteradas: o conteúdo do evento ao vivo de exibição televisiva, com seu repertório que inclui preliminares, discussão intermediária e desfecho; a repetição da câmera lenta em múltiplos ângulos nos momentos de pico e de entusiasmo; as entrevistas seguidas aos grandes lances. São, todas, elementos familiares no léxico do esporte na televisão. O registro de estrelas em primeiro plano já se tornou um elemento rotineiro na cultura de celebridades, cenas que manifestam moda, glamour, saúde, fofocas, cinema de Hollywood, estilo de vida e o ambiente nos estádios de esportes. Na verdade, é difícil imaginar a forma cultural do esporte antes de a televisão ter se tornado seu meio definidor (p. 405).
\end{abstract}

Podemos imaginar muitos historiadores torcendo o nariz para a última frase - sobretudo aqueles familiarizados com a intensa dinâmica associada a jornais, revistas e rádios entre o século XIX e meados do XX. Contudo, o sentido geral do argumento nos parece válido: a transmissão esportiva consolidou-se como um tipo de programa e de fazer televisivo.

\title{
1.2. Convergência e ao vivo por streaming
}

A tecnologia digital está relacionada a mudanças na forma como assistimos não somente aos esportes, mas aos conteúdos audiovisuais em geral. As redes wi-fi e, sobretudo, a potência de transposição de dados obtida com a web 2.0 nos permitiram alternativas aos métodos tradicionais de visualização de conteúdos esportivos (via televisão): por meio de celulares, tablets e outros dispositivos que podem se conectar à internet, inclusive aparelhos televisivos com capacidade de conexão (Kariyawasam e Tsai, 2016). Tais avanços propiciaram, de um lado, flexibilidade e facilidade de acesso, em especial para os interessados em esportes com pouco ou nenhum espaço nas grades televisivas; de outro, custos menores para produção e transmissão de conteúdo ao vivo por meio de plataformas e aplicativos utilizando streaming.

Em síntese, streaming (também chamado de streaming media ou video streaming) é a transferência de "qualquer conteúdo de áudio e/ou vídeo através de uma rede com base em protocolos de Internet” (Kariyawasam e Tsai, 2016). Austerberry (2005) define essa tecnologia como "a transmissão de algum conteúdo de áudio ou vídeo, gerado ao vivo ou pré-gravado,7 direto para o espectador em um fluxo contínuo. Não há necessidade de receber previamente o conteúdo para depois assistir". Esse conceito aplica-se à transmissão de TV (broadcasting), bem como por internet (webcasting).

O streaming apresenta uma diferença básica em relação ao download. O download requer que o computador copie (baixe) o arquivo inteiro no disco rígido antes de poder ser acessado.

7 As transmissões ao vivo combinam imagens geradas ao vivo com outras, pré-gravadas, como imagens de arquivo, replays, reportagens em videoteipe etc. 
Já o streaming não exige que o conteúdo seja armazenado previamente. O usuário visualiza e escuta o conteúdo em tempo real à medida que ele está sendo transferido. A transmissão de conteúdos por streaming a partir de aparelhos móveis como celulares, laptops e tablets, sobretudo quando habilitados para alcance $4 \mathrm{G}$, vem possibilitando um gradual reordenamento nos comportamentos de visualização. Isso, por sua vez, influencia as formas como as redes de televisão consolidadas criam, produzem, agendam e oferecem seus programas (Sorensen, 2016).

Não obstante esse cenário em constante rearranjo, seria precipitado presumir que há necessariamente competição ou regime de excludência entre a transmissão esportiva ao vivo por streaming via internet e o esporte ao vivo difundido por broadcast. França (2009) adverte:

[...] a experiência histórica vem mostrando que novos meios não vêm substituir formas anteriores, mas provocar modificações e adaptações, reconfigurando continuamente o ambiente midiático de uma sociedade. Diferentes mídias se alimentam e se estimulam reciprocamente; a TV tem sabido conviver bem com a Internet, se apropriar de seus recursos e estabelecer com ela uma relação não de concorrência, mas de extensão (p. 28).

Sorensen (2016) afirma que "nunca a TV foi tão assistida ou interagiu tanto como nos dias atuais. Ou, dizendo de modo mais correto, a TV hoje passa muito mais horas ligada nos lares britânicos do que anteriormente". Para ele, a questão central diz respeito a uma espécie de multivisão praticada pela audiência numa variedade de aparelhos simultaneamente, o que demonstraria que mais conteúdos estão sendo consumidos em mais equipamentos.

Uma faceta deste debate que nos parece relevante é apresentada por pesquisadores de uma área ligada a aspectos qualitativos da tecnologia streaming. Eles indicam que a transmissão de vídeo é considerada um dos serviços mais almejados entre usuários com dispositivos portáteis (como smartphones e tablets) que vêm utilizando-os com frequência para fins de entretenimento. Usman et al. afirmam que os usuários querem utilizar a capacidade máxima de seus dispositivos para desfrutar toda qualidade possível de serviços prometidos pelas operadoras. Os autores citam uma pesquisa apontando que, em 2014, a parcela dedicada ao vídeo dentro do tráfego de dados móveis foi de $64 \%$, e provavelmente cresceria nos anos subsequentes.

\subsection{As transmissões por streaming}

O cenário contemporâneo de transmissão de esportes ao vivo é marcado por um intenso consumo e uma oferta cada vez maior de exibições on-line.

Por meio da plataforma da WSL, o usuário "solicita" as imagens para o servidor de multimídia e, após poucos segundos, passa a recebê-las. Pelo webcasting, as imagens de um evento podem chegar a numerosas partes do mundo. Nos últimos anos, a fim de reduzir custos 
de transmissão e de logística, alguns canais de televisão ${ }^{8}$ utilizaram as imagens geradas por essa tecnologia. Contudo, a fluidez na reprodução de imagens mostra-se problemática, se comparada ao sinal de satélite.

Prever o volume de tráfego e provisionar banda de rede suficiente para grandes audiências têm sido os maiores desafios enfrentados por plataformas que utilizam o streaming em transmissões esportivas. $\mathrm{O}$ volume de tráfego e de provisionamento são diferentes para cada provedor, dependendo de questões como localização geográfica, parcerias de rede e número de clientes. As cargas também são diferentes devido a características específicas do evento, como horário e popularidade de cada esporte. Por exemplo, em abril de 2019, por ocasião da primeira transmissão de uma partida de futebol do Flamengo exclusivamente pela rede social digital Facebook, foram bastante noticiados tanto o alto número de acessos quanto os problemas técnicos enfrentados pelos usuários. ${ }^{9}$

Se, de um lado, para lidar com os desafios tecnológicos em busca de audiência as plataformas exibidoras são obrigadas a enfrentar um cenário pouco desenvolvido, de outro, para se comunicar com os web participantes ou fãs ${ }^{10}$, essas mesmas plataformas podem se beneficiar de modelos e de padrões de transmissão esportiva já amadurecidos. É com essa estrutura consolidada na televisão com outras modalidades que o caso do surfe dialoga.

\section{Surfe, cobertura televisiva e transmissão ao vivo por streaming}

A decisão do Comitê Olímpico Internacional de incluir o surfe no programa dos Jogos Olímpicos de verão previstos para Tóquio em 2021 reacendeu um debate em torno da profissionalização do surfe e de sua adesão a formatos altamente esportivizados, comerciais e midiatizados (Fortes, 2011). Disputas simbólicas envolvendo a preservação de uma atividade de lazer integrada à natureza e associada à contracultura versus a massificação de um esporte competitivo com alto apelo estético visual são recorrentes. Na síntese de Booth (2005), tratarse-ia dos

[...] paradoxos de uma cultura que celebra liberdade social, escape do trabalho maçante e interação harmoniosa com a natureza, e que simultaneamente propaga acumulação capitalista, competição e exploração em seus modos de organização econômica e política (p. 105).

As discussões acerca da mercantilização do surfe e da atletização do surfista de alto rendimento propõem indagações a respeito de como televisionar e transmitir o surfe competitivo.

8 Em entrevista concedida a um dos autores deste artigo, em 08/08/2017, o comissário de prova da WSL, Renato Hickel, informou que o canal a cabo ESPN Brasil compra os direitos de transmissão por streaming ao vivo e exibe diretamente para seus assinantes. Trata-se de uma lógica inversa ao que normalmente acontece com transmissões televisivas que são exibidas em dispositivos conectados à internet.

9 Disponível em: <https://www.lance.com.br/flamengo/fla-facebook-transmissao-chega-milhao-views-mas-criticada.html>. Acesso em 9 jan. 2020.

10 Conforme Vimieiro (2019), "por diversas razões históricas e conceituais, pouco foi produzido até o presente momento sobre a relação de torcedores e fãs de esporte em geral com a internet e novas tecnologias" (p. 218). 
Tais questões compõem o contexto em que a Liga Mundial de Surfe decidiu produzir por conta própria e exibir ao vivo via tecnologia streaming todas as competições do Circuito Mundial. Até 2005, quando o Circuito Mundial ainda era regido pela ASP, nenhuma etapa havia sido transmitida ao vivo em sua integralidade, fosse por internet ou televisão.

Transmitir esses campeonatos representa um desafio tecnológico, uma vez que eles possuem particularidades, se comparados a outros tours esportivos. Destacamos quatro delas:

1) Nos últimos anos, algumas etapas do Circuito ocorreram em lugares remotos e/ou periféricos (como Jeffrey's Bay, Fiji, Bali e Taiti), com escassez de infraestrutura tecnológica e de mão de obra técnica com experiência. Esse cenário obriga os organizadores/patrocinadores a custearem as despesas com transporte e acomodação de equipe e equipamentos.

2) Cada etapa tem um período (janela) de 11 dias para ser realizada. Apesar dos avanços nos serviços de previsão meteorológica e das condições do mar (maré, ondulações e vento), frequentemente fases das competições são canceladas e retomadas horas ou dias depois de seu início. Isso decorre do caráter impreciso das previsões climáticas e, em alguns casos, de fenômenos da natureza. A etapa realizada em 2015, em Jeffrey's Bay (África do Sul), por exemplo, teve a final cancelada devido a um incidente envolvendo um tubarão e um dos finalistas. Dois anos depois, uma bateria de quartas de final no mesmo local foi paralisada durante mais de 30 minutos, até que o tubarão flagrado pelos drones e pela equipe responsável pela segurança marinha abandonasse a área da prova. Baterias já foram interrompidas devido à neblina (que impedia que os juízes enxergassem os atletas no mar), ventania e ondas grandes ou pequenas demais, entre outros fatores. De um lado, esse tipo de incidente interfere no cronograma do evento, de outro, gera imagens de impacto que são exploradas midiaticamente.

3) Uma etapa é composta por várias fases. Em cada fase, há baterias com dois ou três surfistas se enfrentando. O tempo total de competição durante uma etapa, somando-se todas as baterias das categorias masculina e feminina, ${ }^{11}$ chega a aproximadamente 60 horas. ${ }^{12}$

4) As regras de competição e os critérios para determinar o vencedor de uma bateria são pouco objetivos ("fluidez de percurso"; "radicalidade de manobras"; "beleza plástica e harmonia durante o trajeto na onda"). Cada onda surfada por um competidor recebe notas (de 0 a 10) de cinco juízes. Esse corpo de jurados é coordenado por um juiz chefe, responsável por orientar e controlar parâmetros numéricos para evitar discrepância de notas. Separados por cabines, os cinco juízes lançam notas individualmente por meio de um sistema informatizado. O número mais alto e o mais baixo são descartados e o surfista recebe a média dos três escores restantes. Não há limite no número de ondas que podem ser surfadas durante uma bateria, mas somente as duas melhores ondas de cada competidor são computadas para que seja designado o vencedor. As notas do julgamento, que são exibidas por inserção de caracteres e grafismos durante a transmissão ao vivo, também são comentadas, avaliadas (e, em raros casos, criticadas e problematizadas) pelos comentaristas, narradores e repórteres.

Ressaltamos que o sistema de competição e julgamento foi descrito em linhas muito gerais nestes parágrafos no intuito de delinear parte da complexidade envolvida na transmissão

11 A maioria das etapas tem campeonatos de homens e mulheres. Em algumas, contudo, há apenas um campeonato (de homens ou de mulheres).

12 A duração das baterias de uma etapa é decidida em função das condições do mar e da previsão de disponibilidade de boas ondas nas horas e dias seguintes - em geral, dura 30 minutos, mas pode ser 25 ou chegar a 45 . Em geral, todas as baterias de uma mesma fase têm a mesma duração - as variações de tempo ocorrem de uma fase para outra. 
e na midiatização de competições de surfe.

\subsection{A plataforma/aplicativo da WSL e seu funcionamento técnico}

A Liga Mundial de Surfe enuncia nos seguintes termos a proposta de transmissão que realiza em sua plataforma digital:

- Trazer o atleticismo, o drama e a aventura do surfe profissional para os fãs de todo o mundo;

- Promover surfistas profissionais como atletas de renome mundial;

- Celebrar a história, a elite dos atletas, a pluralidade dos fãs e os dedicados parceiros que, juntos, incorporam o surfe profissional. ${ }^{13}$

Para que as transmissões ao vivo possam ser visualizadas, o site da empresa dispõe de forma gratuita o download de aplicativos para aparelhos que funcionem com sistemas operacionais Android ou $i O S$. As transmissões podem ser visualizadas em equipamentos móveis conectados à internet por wi-fi ou $4 \mathrm{G}$ e em computadores ou aparelhos televisivos dotados de conexão à web.

Nos computadores ou aparelhos televisivos, o site da plataforma de transmissão pode ser acessado por navegadores como Chrome, Firefox, Safari, Opera e Internet Explorer. Similarmente aos circuitos principais de tênis (ATP e WTA) e de automobilismo (Fórmula 1), as competições acontecem em diferentes continentes e os eventos ao vivo são transmitidos em horários que incidem de forma distinta nos fusos dos diversos países. Por exemplo, uma competição com transmissão ao vivo iniciada às 7 horas da manhã no Havaí é simultaneamente exibida no Brasil a partir das 11 da noite. Tal variação impede muitos interessados de assistirem à transmissão em tempo real, mas eles podem fazê-lo posteriormente graças a recursos da plataforma. A WSL armazena integralmente a transmissão das baterias em seu site. Assim, todo o conteúdo da competição fica arquivado e disponível para acesso durante a temporada anual em curso. ${ }^{14}$ Inclusive, ao se acessar a seção de resultados do site, não aparecem automaticamente os placares das baterias e das fases - isso só se dá após o usuário clicar em "ver notas" -, de forma que é possível assistir aos vídeos sem saber de antemão o resultado.

O cadastramento como usuário não é requerimento obrigatório para que se possa baixar o aplicativo, mas o internauta que opta por informar endereço eletrônico, perfil em redes sociais ou conta em serviços de mensagem recebe e-mail ou alertas sobre as transmissões e pode usufruir das conversas no espaço de chat da WSL. A plataforma estimula o cadastramento e/ou

13 Disponível em: <http://www.worldsurfleague.com/pages/faq>. Acesso em: 3 ago. 2017.

14 Até o momento, trata-se de uma postura inusual entre as entidades esportivas e/ou detentoras dos direitos de transmissão das competições. A nosso ver, essa disponibilidade de fontes torna as transmissões do surfe um objeto ímpar para os interessados em pesquisar diferentes aspectos das relações entre comunicação e esporte. Em março de 2020, o site disponibilizava, na íntegra, as transmissões das etapas dos circuitos de 2015 a 2019. Não sabemos por quanto tempo essa documentação permanecerá disponível de forma aberta e gratuita (ainda mais sendo um acervo completo). 
estabelecimento de vínculos (clicar em "curtir ou "seguir") em redes sociais digitais:

Você também pode se inscrever na nossa lista de endereços para receber alertas de eventos ao vivo e notícias WSL, além de nos seguir nos meios de comunicação social: Facebook: facebook.com/wsl; Twitter: twitter.com/ wsl; Instagram: instagram.com/wsl; Snapchat: worldsurfleague.

Dispositivos móveis como smartphones, tablets e laptops que desfrutam de conexão à internet são equipamentos que combinam múltiplos aplicativos tanto para o usuário assistir conteúdo audiovisual por streaming como para se comunicar em redes sociais. Essas características os distinguem de aparelhos televisivos, mesmo os televisores com capacidade de conexão à internet (smart TVs).

Além de enumerar recursos e particularidades da plataforma da WSL ao transmitir seus eventos ao vivo por streaming, chamamos a atenção para o papel das mídias sociais nas comunidades de esportes radicais como o surfe. Enquanto dispositivos como tablets, celulares e laptops desfrutam da interatividade (envio e recebimento de comentários e dados) e da participação da audiência como um recurso muito presente, o broadcast tradicional precisa recorrer a uma segunda tela para alcançar tal benefício.

Para Thorpe (2016):

Os adeptos dos esportes de ação sempre participaram ativamente do consumo e da produção de meios culturais de nicho. A proliferação de novas tecnologias de mídia está criando um senso de comunidade entre entusiastas e público em contextos locais, nacionais e globais (p. 554).

Como os eventos são transmitidos ao vivo para diversos países e a transmissão incide em diferentes fusos horários, a WSL adota um procedimento padrão: minutos antes das competições se (re)iniciarem, todos os usuários cadastrados recebem no dispositivo com o aplicativo da WSL um alerta (notificação). A divulgação por meio de envio de mensagens também é acionada nas plataformas de mídia social, como o Facebook e o Twitter, e por e-mail.

\section{A transmissão da final da etapa de 2017 na África do Sul}

Em 20 de julho de 2017, na praia de Jeffrey’s Bay, na África do Sul, o surfista brasileiro Felipe Toledo disputou com o português Frederico Moraes o título da $6^{\mathrm{a}}$ etapa do Circuito Mundial. A transmissão ao vivo por streaming na plataforma da WSL foi disponibilizada em inglês e português, e "retransmitida ao vivo" neste último idioma em ao menos dois países por canais de televisão a cabo: Brasil (ESPN Brasil) ${ }^{15}$ e Portugal (Sportv3).

15 A ESPN Brasil transmite os campeonatos dos homens, enfoque deste artigo. Os das mulheres às vezes são transmitidos na íntegra, às vezes não. Há uma notável carência de trabalhos - inclusive em inglês, francês e espanhol - sobre as transmissões dos campeonatos de mulheres no surfe. 
Segundo o comentarista Klaus Kaiser, 70 pessoas fazem parte da equipe de transmissão de uma etapa. ${ }^{16}$ Esse número refere-se a jornalistas, comentaristas, cinegrafistas, editores, técnicos em computação gráfica e repórteres. Os eventos são captados e transmitidos por seis ${ }^{17}$ câmeras - incluindo câmera aquática, drone e eventualmente câmeras de ação acopladas aos surfistas. ${ }^{18}$ Para termos um parâmetro: referindo-se à transmissão de partidas de futebol na televisão aberta brasileira, Ushinohama e Affini (2010) afirmam que "um evento externo precisa de um estúdio sobre rodas, um grande suporte técnico e um competente recurso de engenharia para transmitir direto e ao vivo" (p. 6). Segundo consulta a um comunicólogo que trabalha numa das principais redes de televisão do país, uma transmissão ao vivo na TV aberta envolve entre 50 e 60 profissionais, podendo chegar próximo a 100 em partidas particularmente importantes. ${ }^{19}$ A pesquisadora Tatiana Ushinohama fez as mesmas estimativas, inclusive na diferença do total de trabalhadores envolvidos entre "um jogo no meio do campeonato" e "a final". ${ }^{20}$

Para auxiliar a compreensão do objeto de que estamos falando, fizemos uma decupagem e elaboramos categorias gerais (não excludentes), apresentadas na Tabela $1 .{ }^{21} \mathrm{~A}$ transmissão durou 50 minutos, sendo 40 de disputa da bateria.

16 Entrevista por telefone concedida a um dos autores do artigo, em agosto de 2017, pelo comentarista Klaus Kaiser, que integra a equipe das transmissões.

17 Este número pode variar para menos ou para mais.

18 Entrevista por telefone concedida a um dos autores do artigo, em agosto de 2017, pelo comentarista Klaus Kaiser, que integra a equipe das transmissões.

19 O profissional solicitou que não citássemos seu nome. Troca de e-mails com um dos autores deste artigo em março de 2020.

20 Troca de e-mails com um dos autores deste artigo em março de 2020.

21 Realizamos a decupagem de um arquivo audiovisual com 50 minutos de duração coletado no endereço: $<\mathrm{http}: / / \mathrm{www}$. worldsurfleague.com/events/2017/mct/1900/corona-open-j-bay/heatanalyzer>. Acesso em 22 mar. 2020. 
Tabela 1: Decupagem da transmissão da final

\begin{tabular}{cc}
\hline $\begin{array}{c}\text { Tempo total durante a } \\
\text { transmissão }\end{array}$ & O que está na tela / recursos visuais \\
\hline 30 segundos & Apresentação prévia dos finalistas. \\
5 min47seg & Transmissão ao vivo das ondas surfadas. \\
15 min24seg & Replay de ondas surfadas. \\
34 min20seg & $\begin{array}{c}\text { Inserção de grafismos: notas de juízes, dados sobre competidores } \\
\text { (peso, altura, país, posição no ranking; colocações obtidas na etapa } \\
\text { em anos anteriores etc.). }\end{array}$ \\
& $\begin{array}{c}\text { Entrevistas com o treinador do surfista Frederico Moraes e com o } \\
\text { campeão mundial de 2016, John John Florence. Tais entrevistas } \\
\text { foram exibidas em formato picture in picture (tela sobre tela), de } \\
\text { modo que a transmissão das ondas surfadas pudesse ser acompa- } \\
\text { nhada caso ocorressem no mesmo instante, o que não chegou a } \\
\text { acontecer (ver Imagem 1).22 }\end{array}$ \\
& Premiação do surfista vencedor e do segundo colocado. \\
\hline 9min50seg &
\end{tabular}

Imagem 1 - Picture in Picture

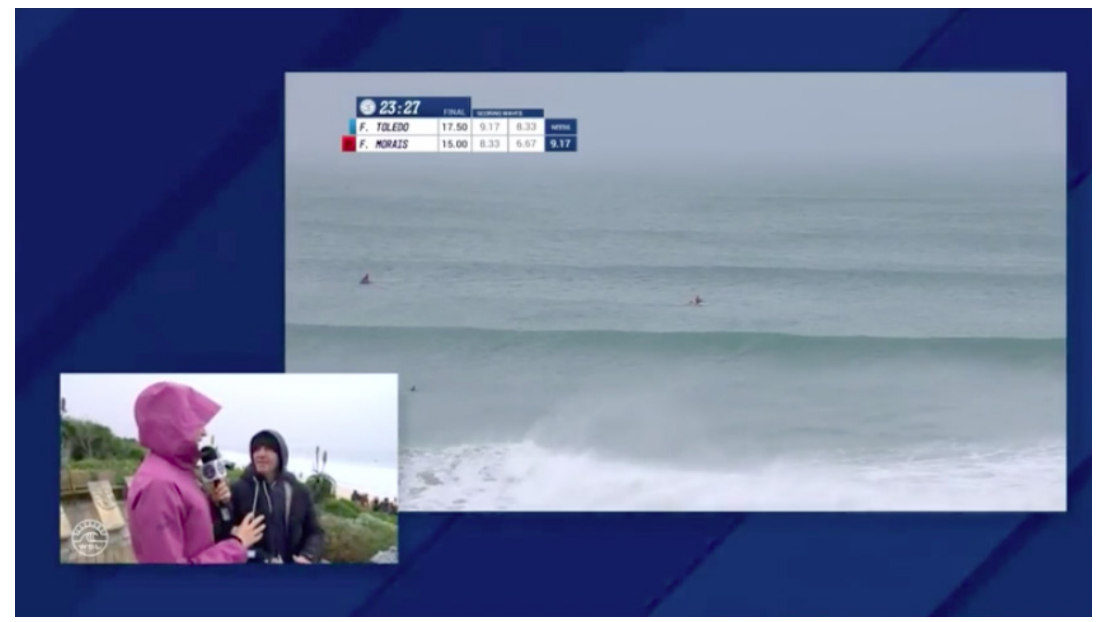

Cada transmissão de final começa com uma retrospectiva de 30 segundos apresentando os contendedores. Trata-se de uma edição montada com trechos de imagens captadas e arquivadas em fases anteriores. Segundo a perspectiva de Feuer (1983, apud Marriott, 1996), a utilização de imagens pré-arquivadas junto aos comentários e aos grafismos sobrepostos em

22 Dentro da transmissão de uma bateria, inclusive da final, há pausa para intervalos comerciais. Ou seja, a final continua (no surfe a contagem regressiva de tempo é contínua), mas a tela é ocupada por áudio e vídeo de comerciais. Caso se perca uma onda ou acontecimento considerado importante pela produção, ele é inserido em replay. Parece haver aqui uma diferença em relação às transmissões televisivas, no Brasil, da maioria das modalidades, nas quais a inserção de comerciais que interrompem áudio e vídeo ao vivo do jogo/esporte só se dá durante pausas na disputa (entre games ou sets, no tênis; durante pedidos de tempo e entre quartos, no basquete; etc.). 
tela, em transmissão esportiva, caracterizaria um "evento televisivo altamente empacotado" e, por consequência, não inteiramente "ao vivo".

\begin{abstract}
Os programas de esporte, tal qual outros formatos ao vivo, como os boletins de notícias, contêm grandes segmentos de material gravado [...] Esses segmentos são "ao vivo" apenas no sentido restrito de que o tempo de transmissão coincide com o tempo de recepção [...] É E alternância desses segmentos com material "ao vivo" - a participação dos apresentadores; as discussões nas entrelinhas e a transmissão do próprio evento "como acontece" - que traz um aspecto de "colagem" de filme, vídeo e do "ao vivo" ao qual Feuer se refere (Marriott, 1996).
\end{abstract}

Esse caráter de "colagem", alternando material pré-gravado e tomadas ao vivo, não faria tanto sentido se os comentaristas não lançassem mão do uso do tempo presente em seus comentários, mesmo quando se referem a uma imagem que não está sendo transmitida enquanto acontece:

Tabela 2: Trechos da transmissão da final

\begin{tabular}{ccc}
\hline Trecho & Áudio (Narração de Joe Turpel) & Vídeo \\
\hline 1 & $\begin{array}{c}\text { Vejam aí o cara que representa Por- } \\
\text { tugal! Rasga a onda em sua primeira } \\
\text { virada! Frederico tem uma seleção de } \\
\text { ondas impecável! }\end{array}$ & $\begin{array}{c}\text { Imagens pré-gravadas de Frederico Moraes } \\
\text { surfando em dias anteriores mais imagens } \\
\text { do público torcedor levantando cartelas com } \\
\text { notas simulando um julgamento. }\end{array}$ \\
2 & $\begin{array}{c}\text { Felipe Toledo: o jeito que ele surfa } \\
\text { é tão à vontade mexendo seu equi- } \\
\text { pamento na onda! Tanta pressão } \\
\text { colocada na rabeta da prancha nessa } \\
\text { manobra! }\end{array}$ & $\begin{array}{c}\text { corta para Felipe Toledo concentrado olhan- } \\
\text { do o mar. Imagens pré-gravadas dele com- } \\
\text { petindo em fases anteriores mais inserções } \\
\text { de vinhetas gráficas finalizando o trecho da } \\
\text { "retrospectiva" e fazendo transição para a } \\
\text { transmissão ao vivo. }\end{array}$ \\
& $\begin{array}{c}\text { É o grande momento pelo qual espe- } \\
\text { rávamos! A final do Corona Jeffrey’s } \\
\text { Bay está começando! }\end{array}$ & $\begin{array}{c}\text { Plano geral do campeonato, com público } \\
\text { assistindo da areia e do palanque de com- } \\
\text { petição. Em seguida corta para a imagem } \\
\text { do narrador e do comentarista que falam ao } \\
\text { vivo sentados com fones de ouvido. }\end{array}$ \\
\hline
\end{tabular}

Em seguida ao trecho 3 acima, o narrador Joe Turpel apresenta a si mesmo e ao comentarista, "o ex-campeão mundial Martin Potter" (também conhecido como Pottz). Tratase de um esquema similar ao já consolidado em transmissões esportivas, em que vemos dois comentaristas sentados lado a lado (exceto que não estão atrás de uma bancada), conforme a imagem a seguir. 
Imagem 2: Joe Turpel e Martin Potter, narrador e comentarista da transmissão em inglês.

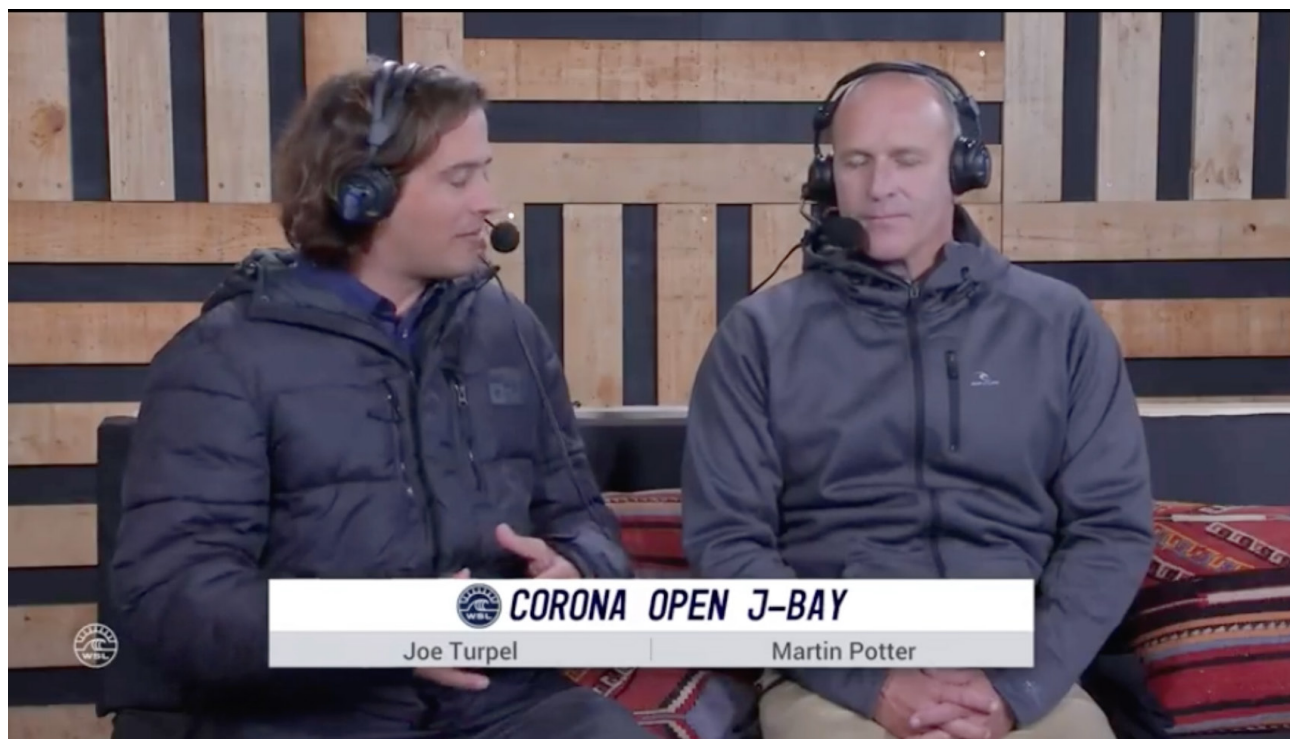

Logo depois de se apresentarem e trocarem poucas frases, aparece o seguinte:

Tabela 3: Trechos da transmissão da final

\begin{tabular}{ccc}
\hline Trecho & Áudio & Vídeo \\
\hline & Turpel: Pottz, o palco está pronto. Tivemos & \\
várias notas 10. Os dois atletas mais prepara- & Computação gráfica mostrando \\
dos até aqui vão brigar por um prêmio pres- & fotos do rosto dos dois surfistas na \\
tigiado: 10 mil pontos no ranking Jeep e 100 & final com as respectivas bandeiras \\
mil dólares. Vamos ver como será o desenrolar & de seus países e seus nomes sobre- \\
dessa disputa. Duas escolas diferentes de surfe & postos à imagem das ondas ao vivo \\
na forma como abordam o estilo dessa onda. & (Imagem 3). Essa sobreposição de \\
& Potter: Pois é... exatamente... Duas maneiras & imagens perdura durante 30 segun- \\
diferentes de abordar a onda [...] & dos de comentários. \\
\hline
\end{tabular}


Imagem 3: Grafismos com imagens dos finalistas

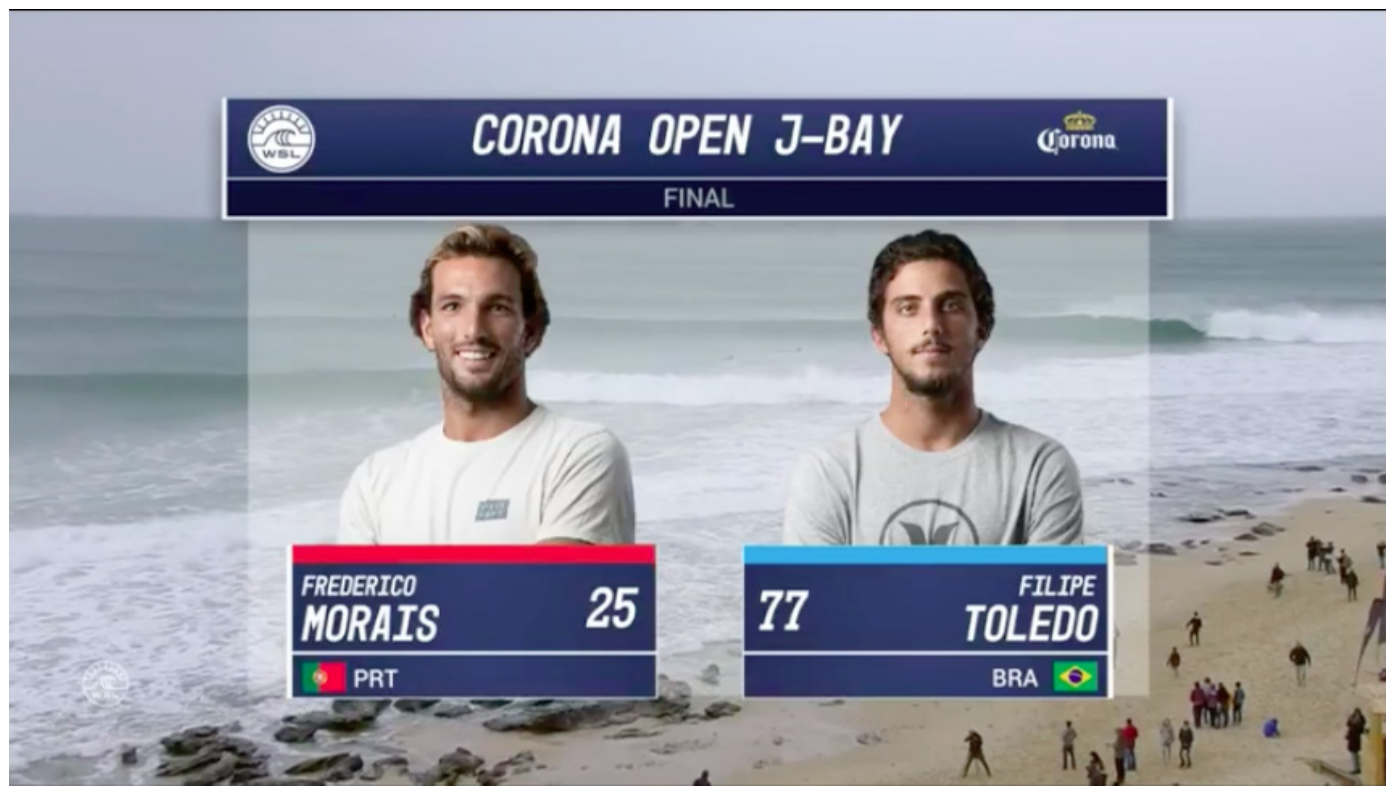

Os recursos não parecem diferir daqueles utilizados para introdução dos contendedores em transmissões televisivas de lutas de boxe e MMA ou partidas de tênis, por exemplo.

Essas falas introdutórias e as do minuto subsequente, a respeito da primeira onda surfada na final por cada atleta, ${ }^{23}$ embaralham três dimensões estudadas pela narratologia: crônica, mimese e enredamento. Segundo Ryan (1993):

Enquanto crônica, a narrativa enumera eventos e satisfaz a curiosidade do leitor para $o$ que acontece no universo em questão. Na dimensão mimética, o texto se concentra no como. Neste caso, a narrativa confere presença e vivacidade ao evento narrado e permite que os "leitores" (espectadores/ ouvintes) formem uma imagem mental através da qual eles possam participar de maneira indireta nos eventos. $\mathrm{O}$ aspecto de enredamento, por fim, organiza o narrado em um "desenho estrutural" que torna os eventos inteligíveis para o público. Através deste "desenho estrutural", o texto narrativo satisfaz a demanda do leitor (espectador/ouvinte) para o porquê dos eventos. O desenvolvimento proporcional dessas três dimensões é altamente variável entre os diversos tipos de textos narrativos e aponta as diferentes formas de abordagem.

Nas transmissões da WSL observamos uma predominância narrativa de crônica. Esse modo talvez se deva ao caráter imprevisível, tanto das disputas esportivas em geral quanto da subjetividade envolvida na atribuição de notas e determinação de um vencedor nas disputas entre surfistas. Não são poucas as situações em que o resultado determinado pelos juízes gera polêmicas e reclamações por parte dos competidores envolvidos e, sobretudo, do público que 
assiste às transmissões ${ }^{24}$

Diante dessas circunstâncias, os comentaristas e narradores são orientados pela WSL a evitar emitir juízo de valor sobre as notas atribuídas pelos juízes. ${ }^{25}$ Para adotar uma narração compatível com os critérios e as exigências da WSL, os comentaristas são orientados para que evitem especular, logo após a onda ser surfada, sobre qual será a nota do competidor. Segundo Renato Hickel, chefe dos juízes da WSL, "o ideal é que o comentarista aguarde que os juízes lancem a nota para que possa debater o assunto". Isso gera um desafio aos que falam durante a transmissão: permanecer numa zona de fronteira entre a mediação, o entretenimento e a abstenção de avaliação sobre as notas. ${ }^{26}$ Para Ryan (1993), "de todas as formas de representação verbal, nenhuma requer tanta simultaneidade quanto a transmissão esportiva ao vivo. A transmissão esportiva ao vivo pode ser comparada a um programa de computador operando em tempo real."

Apesar de a orientação da WSL visar à inibição de polêmicas em desfavor do corpo dos juízes, alguns comentaristas acabam apresentando suas posições de forma indireta:

Potter: Toledo precisaria de um 8,8 para ampliar sua vantagem sobre Moraes... Não acho que ele tenha conseguido essa nota...

Turpel: A última onda do Toledo foi 7,6, Pottz. Como você imaginou, não mudou os pontos que o Moraes precisa para virar. Será que ele vai ter outra chance?

Outro elemento presente no comentário nas transmissões de surfe consiste em fomentar o caráter de imprevisibilidade de um embate esportivo, reforçando a ideia de uma disputa não decidida - mesmo que, às vezes, retrospectivamente. Nos segundos finais da competição, o comentarista Martin Potter fala em tom celebrativo:

Que final! Com múltiplas mudanças de líder. Frederico marcou 9,4 em uma onda, assumiu a liderança, mas a resposta de Toledo foi importante para recolocá-lo na liderança. E o campeonato termina. Um dos melhores eventos que já tivemos em Jeffrey’s Bay. O Corona Open J'Bay vai para Felipe Toledo!

Após essa caracterização da bateria final como uma disputa cujo resultado esteve sempre em aberto, seguiram-se 10 minutos de transmissão, incluindo a cerimônia de premiação. Em seguida, entrou no ar um "pós-show" com duração de cerca de 30 minutos.

24 Em várias etapas, é comum haver na janela de chat disponibilizada pela plataforma WSL numerosas mensagens de descontentamento com o julgamento.

25 Entrevista por telefone concedida a um dos autores do artigo, em agosto de 2017, pelo comentarista Klaus Kaiser, que integra a equipe das transmissões.

26 A tarefa de narrar torna-se, portanto, ainda mais complicada. 


\section{Considerações finais}

Para além de uma forma tecnológica de difusão de eventos esportivos no exato momento em que eles acontecem, a transmissão televisiva de esportes ao vivo constitui um fenômeno social complexo e amplamente disseminado. Sua consolidação, fortalecida ao longo de décadas pela transmissão em esfera global de megaeventos como Jogos Olímpicos e Copas do Mundo de futebol masculino - mas também de eventos com popularidade específica entre regiões do mundo e/ou setores da população, como certas disputas de boxe, críquete, tênis, golfe, ciclismo, hóquei no gelo e automobilismo -, difundiu comportamentos narrativos e formas de mostrar que percebemos nas transmissões de surfe por streaming ao vivo.

Nas transmissões da plataforma WSL, identificamos um certo embaralhamento entre a importação de modelos do esporte televisivo e a experimentação de exibir uma competição de surfe para a comunidade de surfistas, apreciadores e novos espectadores espalhados por todos os continentes. A nosso ver, esse embaralhamento ocorre, sobretudo, por se tratar de uma ação inovadora - durante o século XX, nenhuma competição mundial de surfe fora transmitida na íntegra para diversos países por televisão com sistema broadcast.

De um lado, diversos componentes do "léxico" da transmissão esportiva do ao vivo televisivo elencados por Whannel (2005), como "preliminares, discussão intermediária e desfecho; a repetição da câmera lenta em múltiplos ângulos nos momentos de pico e de entusiasmo; o registro de estrelas em primeiro plano, celebridades, cenas que manifestam moda, glamour, saúde, [...] estilo de vida", estão presentes na transmissão por streaming da WSL, sugerindo uma importação de padrões gerais. De outro, ao lançar mão de câmeras de ação, drones, câmeras aquáticas, janelas para interatividade on-line entre fãs, contratação de comentaristas não oriundos do campo do jornalismo, entre outras medidas, a WSL performa experimentalmente na transmissão ao vivo. Ao praticar tais inovações, a empresa não somente investe na retórica da "plasticidade singular" do surfe, como reitera a fala sobre si que reivindica um papel central na promoção desse esporte, do circuito e dos atletas, conforme discutido no item 2.1.

Emissoras de TV a cabo retransmitindo o streaming dos campeonatos de surfe, bem como o embaralhamento entre as incidências do esporte ao vivo televisivo e as experimentações da transmissão da WSL, também podem ser vistas como desdobramentos da polêmica imbricação entre televisão broadcast e televisão convergente. A questão requer exame específico, devido à multiplicidade de entrelaçamentos entre TV e internet, inclusive na área esportiva. No Brasil, ela carece de aprofundamento nos estudos do esporte na Comunicação - que dirá nos estudos históricos do esporte.

Ao abordar alguns problemas e desenvolver outros, este artigo busca contribuir para o desenvolvimento dos estudos históricos do esporte no Brasil, os quais enfatizam muito os periódicos impressos, mas pouco se debruçaram, até hoje, sobre as programações radiofônica e televisiva, incluindo as transmissões ao vivo, bem como sobre seus aspectos narrativos e os modos pelos quais tais formas de contar/narrar/transmitir o espetáculo esportivo mediaram nossas compreensões desse fenômeno popular (Melo et al., 2013; Santos, 2013). Uma exceção é a coletânea organizada por Hollanda et al. (2013).

A inexistência, até o momento, de trabalhos científicos que estabeleçam o que é o padrão de transmissão de esportes (nem sequer o de futebol) ao vivo na televisão brasileira impõe limites a nosso esforço de caracterização das transmissões do surfe e de exploração 
de possíveis particularidades. Sobretudo na Comunicação, há exceções enfocando casos específicos (Ushinohama, Affini, 2010; 2011).

Os principais avanços ao tratar de aspectos técnicos, estéticos, imagéticos e narrativos foram realizados por Silveira (2013) e Ushinohama (2014). Discussões sobre que sons e imagens formam a transmissão quando a bola está parada e sobre posicionamento de câmera e enquadramento das imagens que preenchem as transmissões estão entre as relevantes contribuições desses trabalhos. São dissertações de mestrado valorosas, voltadas para a partida derradeira da fase final das Copas do Mundo de futebol masculino, que ocupa um de cada 48 meses do calendário esportivo, ${ }^{27}$ e com as limitações de escopo de pesquisas finalizadas em dois anos.

Por fim, este artigo evidencia como a abordagem de novos objetos e recortes temporais permite lançar novas questões para os estudos históricos do esporte. Ao nos aproximarmos do final do século XX e adentrarmos no XXI, torna-se mais difícil separar o campo esportivo de sua mediação pelos meios de comunicação - ambos, aliás, integrantes do mercado de entretenimento, ainda que o discurso purista de muitos jornalistas e de alguns pesquisadores tenda a localizar a cobertura esportiva exclusivamente no âmbito jornalístico - em tese, separado da opinião e do entretenimento. A abordagem de experiências do exterior, bem como o uso de bibliografia dando conta da história das transmissões esportivas em diferentes países e continentes, também contribui para jogar luz sobre as especificidades (ou não) do que ocorre no Brasil, seja nas transmissões próprias, seja nas retransmissões - com variados graus de intervenção e adaptação, como é o caso da veiculação em português das transmissões por streaming de competições da WSL.

\section{Referências bibliográficas}

AUSLANDER, Philip. Liveness: Performance in a mediatized culture. $2^{\text {nd }}$. Edition. London: Routledge, 2008.

AUSTERBERRY, David. The Technology of Video \& Áudio Streaming. Burlington: Focal Press, 2005.

BOOTH, Douglas. Paradoxes of Material Culture: The Political Economy of Surfing. In: NAURIGHT, John; SCHIMMEL, Kimberly S. (ed.) The Political Economy of Sport. Basingstoke and New York, Palgrave Macmillan, 2005, p. 104-25.

BOYLE, Raymond; HAYNES, Richard. Power Play: Sport, the Media and Popular Culture. 2nd. ed. Edinburgh: Edinburgh University Press, 2009.

CAUGHIE, John. Television drama: Realism, modernism, and British culture. Oxford: Oxford University Press, 2000.

27 Isto é, abordam exceções (uma partida disputada a cada 48 meses) e não a regra (as transmissões realizadas durante 47 meses a cada quatro anos de disputas futebolísticas). 
FORTES, Rafael. O surfe nas ondas da mídia: esporte, juventude e cultura. Rio de Janeiro: Apicuri, 2011.

GOLDLUST, John. Sport as Entertainment: The Role of Mass Communication. In: ROWE, David (ed.). Critical Readings: Sport, Culture and the Media. Maidenhead: Open University Press, 2004, p. 27-47.

GRUNEAU, Richard. Making Spectacle: A Case Study in Television Sports Production. In: WENNER, Lawrence (ed.). Media, Sports \& Society. Newbury Park: Sage, 1989, p. 134-154.

FRANÇA, Vera V. A Televisão Porosa - Traços e Tendências. In: FREIRE FILHO, João (org.). A TV em transição: tendências de programação no Brasil e no mundo. Porto Alegre: Sulina, 2009.

HOLLANDA, Bernardo Borges Buarque de et al. (Org.). Olho no lance: ensaios sobre esporte e televisão. Rio de Janeiro: 7 Letras, 2013.

Kariyawasam, Kanchana; TSAI, Matthew. Copyright and live streaming of sports broadcasting. International Review of Law, Computers \& Technology. Vol. 31, n. 3, p. 265-288, 2017.

KINKEMA, Kathleen M.; HARRIS, Janet C. MediaSport Studies: Key Research and Emerging Issues. In: WENNER, Lawrence (ed.). MediaSport. London: Routledge, 1998, p. 27-54.

MACHADO, Arlindo. A televisão levada a sério. São Paulo: Senac, 2000.

MARRIOTT, Stephanie. Time and time again: "live" television commentary and the construction of replay talk. Media, Culture \& Society. January 1, 1996.

MATTOS, Sérgio. História da televisão brasileira. 2a ed. Petrópolis: Vozes, 2002.

MELO, Victor Andrade de. Causa e consequência: esporte e imprensa no Rio de Janeiro do século XIX e década inicial do século XX. In: HOLLANDA, Bernardo Borges Buarque de; MELO, Victor Andrade de (Org.). $O$ esporte na imprensa e a imprensa esportiva no Brasil. Rio de Janeiro: 7 Letras, 2012, p. 21-51.

MELO, Victor Andrade de et al. Pesquisa histórica e história do esporte. Rio de Janeiro: 7 Letras/Faperj, 2013.

MELO, Victor Andrade de. Cidade Sportiva: primórdios do esporte no Rio de Janeiro. Rio de Janeiro: Relume Dumará/FAPERJ, 2001.

MILLER, Toby et. al. Globalization and Sport. London: Sage, 2001.

ROWE, David (ed.). Critical Readings: Sport, Culture and the Media. Maidenhead: Open University Press, 2004. 
RYAN, Marie-Laure. Narrative in Real Time: Chronicle, Mimesis and Plot in the Baseball Broadcast. Narrative. Vol. 1, n. 2, p. 138-155, May 1993.

SANTOS, João M. C. Malaia. Televisão paga e as 24 horas do mundo esportivo. In: HOLLANDA, Bernardo Borges Buarque de; SANTOS, João Manuel Casquinha Malaia dos; TOLEDO, Luiz Henrique de; MELO, Victor Andrade de (Org.). Olho no lance: ensaios sobre esporte e televisão. Rio de Janeiro: 7 Letras, 2013, p. 148-167.

SORENSEN, Inge Ejbye. Content in context: The impact of mobile media on the British TV industry. Convergence: The International Journal of Research into New Media Technologies. 2016. Disponível em: <https://journals. sagepub.com/doi/full/10.1177/1354856516681703>. Acesso em 15 mar. 2020.

SILVEIRA, Márcio Telles da. A recriação dos tempos mortos no futebol pela televisão: molduras, moldurações e figuras televisivas. Dissertação (Mestrado em Comunicação e Informação) - Universidade Federal do Rio Grande do Sul, Porto Alegre, 2013.

THORPE, Holly. Action Sports, Social Media, and New Technologies: Towards a Research Agenda. Communication \& Sport, v. 5, n. 5, p. 554-578, March 2016. Disponível em: <https://doi.org/10.1177/2167479516638125>. Acesso em 31 mar. 2020.

USHINOHAMA, Tatiana Zuardi. A narrativa audiovisual da transmissão direta e "ao vivo” da Copa do Mundo da FIFA: comparação entre a televisão analógica e a digital. Dissertação (Mestrado em Comunicação). Universidade Estadual Paulista Júlio de Mesquita Filho, Bauru, 2014.

USHINOHAMA, Tatiana Zuardi; AFFINI, Letícia Passos. Futebol: aspectos da linguagem audiovisual nas transmissões esportivas. Anais do XV Congresso de Ciências da Comunicação na Região Sudeste. Intercom: Vitória, 2010. Disponível em: <http://intercom.org.br/papers/regionais/sudeste2010/resumos/R19-1020-1.pdf>. Acesso em 24 mar. 2020

USHINOHAMA, Tatiana Zuardi; AFFINI, Letícia Passos. Gerenciamento de uma transmissão televisiva futebolística após um Megaevento. Anais do XVI Congresso de Ciências da Comunicação na Região Sudeste. Intercom: São Paulo, 2011.

Disponível em: <http://www.intercom.org.br/papers/regionais/sudeste2011/resumos/R24-0446-1.pdf>. Acesso em 24 mar. 2020.

USMAN, Muhammad Arslan et al. A No Reference Video Quality Metric Based on Jerkiness Estimation Focusing on Multiple Frame Freezing in Video Streaming. IETE Technical Review, v. 34, n. 3, p. 309-320, 8 Jun. 2016.

VIMIEIRO, Ana Carolina. A produtividade digital dos torcedores de futebol brasileiros: formatos, motivações e abordagens. In: FORTES, Rafael; VIANA, Juliana de Alencar (org.). Repensando o lazer a partir da cultura digital. Rio de Janeiro: Epapers, 2019, p. 217-252. 
WHANNEL, Garry. Pregnant with anticipation: The pre-history of television sport and the politics of recycling and preservation. International Journal of Cultural Studies. December 1, 2005.

WHANNEL, Garry. Fields in vision: television sport and cultural transformation. London and New York: Routledge, 1992.

RECEBIDO EM: 31/03/2020

APROVADO EM: 23/04/2020 